\title{
Cytogenetic Analysis and Clinical Phenotype of Primary Amenorrhea in Indonesian Patients
}

\author{
Aisha Ali ${ }^{1 *}$, Rita Indriyati², Tri Indah Winarni², Sultana MH Faradz ${ }^{2}$ \\ ${ }^{1}$ Student of Genetic Counseling, Master of Biomedical Science, Faculty of Medicine Diponegoro University, \\ Semarang, Central-Java, Indonesia \\ ${ }^{2}$ Center for Biomedical Research (CEBIOR), Faculty of Medicine Diponegoro University, Semarang, Central- \\ Java, Indonesia
}

\section{Article Info}

History:

Received: 19 Apr 2018

Accepted: 06 July 2018

Available: 31 July 2018

\begin{abstract}
Background: Primary amenorrhea (PA) is a symptom that can be caused by different disorders such as gonadal, endocrinal, physiological and genetic disorders.

Objectives: This study provided the clinical and cytogenetic profiles of Indonesian primary amenorrhea patients and matching the clinical criteria of those patients with their karyotype results by using a new scoring system.

Methods: A retrospective descriptive study of 79 PA patients, whom referred to Cytogenetic and Molecular unit Center for Biomedical Research (CEBIOR), Faculty of Medicine Diponegoro University. We made a scoring system consisted of 4 scores, all patients had been distributed to match the scores according to their clinical criteria's and then confirmed with the karyotype results.

Results: The karyotype results of 79 patients of PA revealed 55 (69.6\%) patients with female karyotype 46,XX; $6(7.6 \%)$ patients with male karyotype 46,XY; $8(10.1 \%)$ patients with monosomy $\mathrm{X} ; 3$ (3.8\%) patients with 45,X/46,XX; 3 (3.8\%) patients with Isochromosome $45 \mathrm{X} / 46, \mathrm{X}, \mathrm{i}(\mathrm{Xq})$. Mosaicism with $\mathrm{Y}$ constitution $45, \mathrm{X} / 46, \mathrm{XY}$ was seen in $2(2.5 \%)$ patients; marker chromosome $45, \mathrm{X} / 46, \mathrm{X}+\mathrm{mar}(2 \%)$ in 1 patient $(1.3 \%)$; and chromosome 1 and $\mathrm{X}$ translocation $46, \mathrm{XX}, \mathrm{t}(1 ; \mathrm{X})(\mathrm{p} 34 ; \mathrm{q} 25)$ detected in

$1(1.3 \%)$ patient. Scoring system results showed that all patients with normal karyotype $(46, \mathrm{XX} / 46, \mathrm{XY})$ were matched with score 1 and 2 while 17 patients with chromosomal abnormalities were matched with score 3 and 4, only 1 patient with mosaic Turner syndrome 45,X(10\%)/46,XX(90\%) matched score 1 .

Conclusion: Turner syndrome was the most common cause of primary amenorrhea, which attests the importance of cytogenetic analysis for diagnosis of primary amenorrhea patients. The scoring system needs further validation for measuring reliability and validity.
\end{abstract}

Keywords: primary amenorrhea; karyotype; clinical phenotype; score system

\section{INTRODUCTION}

Primary amenorrhea defined as failure of menarche, associated with undeveloped secondary sexual signs by age 14 , or failure of menarche with well-developed secondary sexual signs by age $16 .{ }^{1}$ It is a symptom that caused by different disorders. ${ }^{2,3}$ The worldwide incidence estimated to be $1 \%,{ }^{4,5}$ and based on research results from different countries, there was no evidence for higher frequency in a specific population or ethnic group. ${ }^{3}$

A number of studies estimated the frequency of primary amenorrhea based on the causes including gonadal dysgenesis was due to chromosomal abnormalities as the largest cause accounting in $45 \%$, followed by Mayer Rokitanski Kuser Hauser 
* Corresponding author:

Sultana MH Faradz

E-mail: sultanafaradz@gmail.com

syndrome (MRKH) in 15\%, and Hypothalamic Idiopathic HypogonadotropicHypogonadism (IHH) was estimated to be $15 \%$. Complete androgen insensitivity syndrome (CAIS) assessed for $10 \%$ of all primary amenorrhea patients, ${ }^{7}$ imperforated hymen and transverse septum hymen reported to be $5 \%,{ }^{8}$ while the remaining $5 \%$ was distributed among congenital adrenal hyperplasia $(\mathrm{CAH})$ and ovarian insensitivity syndrome. ${ }^{3}$ Mullerian Agenesis-Mayer Rokitansky-Kuster-Hauser Syndrome (MRKH) has a prevalence of 1:5000 female births. $^{6}$ Affected individuals have a 46,XX karyotyping and a normal secondary sex characteristics. Type A (MRKA) patients show Symmetric uterine buds and fallopian tubes. Type B (MRKH) shows asymmetric uterine buds and fallopian tubes and being associated with other congenital anomalies (skeletal, renal, ovarian, ear and cardiac). ${ }^{6,9}$

This is the first study in Indonesia to provide the profiles of primary amenorrhea patients including the karyotype results and their clinical profiles. The new of this study that we made a scoring system and the patients had been distributed to match the scores according to their clinical criteria and then confirmed it with their karyotype results. This scoring system can help to distinguish roughly possible karyotype results in situation of deficient genetic facilities before cytogenetic analysis hold out. Scoring system can be used to predict that PA patient with normal secondary sexual signs can be female or male karyotype results and cannot be a chromosomal abnormality based on clinical phenotypes. In contrast, PA with poor secondary sexual development with short stature and web neck can predict of chromosomal abnormalities. However, this scoring system still needs further studies to measure validity and reliability, and whether it could be used as a tool to predict the clinical phenotype and the genetic cause/karyotype.

\section{METHODS}

\section{Population and Sample}

The sampling method was purposive sampling; patients had been selected according to the purpose of the study. All patients who referred to CEBIOR with primary amenorrhea and had available data, with the criteria: thirteen years old with undeveloped secondary sexual signs or 16 years old with welldeveloped secondary sexual signs. All patients with inclusioncriteria Whom referred to Cytogenetic and Molecular unit Center for Biomedical Research (CEBIOR), Facultyof Medicine Diponegoro University from the period of January 2004 to January 2017 were included in this study.

In this study we made a scoring system consisted of clinical criteria and karyotype results the score system had 4 scores, score 1 for primary amenorrhea symptom only, score 2 for primary amenorrhea and poor secondary sexual signs, score 3 for primary amenorrhea, poor secondary sexual signs and short stature, score 4 for primary amenorrhea, poor secondary sexual signs, short stature, and webbed neck. The clinical data was obtained from the medical records and were grouped into the scoring system. Patients without complete cytogenetic and clinical data were excluded. All the patients had been distributed to match the scores according to their clinical profiles and then confirmed with the karyotype results.

Poor secondary sexual signs considered if Tanner stage less than 4 with spare or absent axillary hair. Short stature considered if the height is below 2 slandered deviation of the mid parental hight.

Chromosomal analysis had been performed by blood as a usual method in CEBIOR.

Table 1. Scoring system for primary amenorrhea patients

$\mathrm{PA}=$ primary amenorrhea

Poor secondary sexual signs $=$ Tanner stage less than 4 with spare or abscent axillary hair

\begin{tabular}{cl}
\hline Score & Clinical Criteria \\
\hline 1 & PA \\
2 & PA, poor secondary sexual development \\
3 & $\begin{array}{l}\text { PA, poor secondary sexual development and short } \\
\text { stature }\end{array}$ \\
4 & $\begin{array}{l}\text { PA, poor secondary development, short stature, } \\
\text { webbed neck. }\end{array}$ \\
\end{tabular}

\section{RESULTS}

Seventy nine PA patients were included in this study. The distribution of patients according to the karyotype revealed that $55(69.6 \%)$ of patients had 46 , XX karyotype; 6 (7.6\%) patients had 46, XY karyotype, and $18(22.8 \%)$ patients with chromosomal abnormalities as showed in Figure 1.

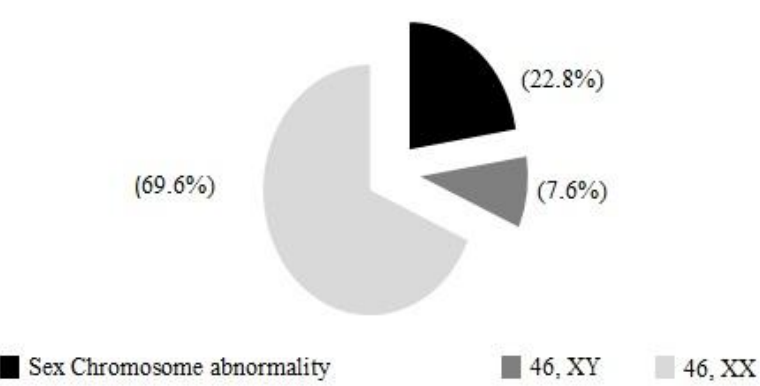

Figure 1. Distribution of karyotype results in primary amenorrhea patients

The most frequent chromosomal abnormalities was $45, \mathrm{X}$ in $10.1 \%$ followed by $45, \mathrm{X} / 46, \mathrm{XX}$ mosaicism in $3.7 \%$. Isochromosomemosaicism of $45, \mathrm{X} / 46, \mathrm{X}, \mathrm{i}(\mathrm{Xq})$ accounted in $3.8 \%$. Mosaicism with $\mathrm{Y}$ constitution 45,X/46,XY was found in 2 patients $2.5 \%$; marker chromosome $45, \mathrm{X} / 46, \mathrm{X}+\operatorname{mar}(2 \%)$ in 1 patient and chromosome 1 and $\mathrm{X}$ translocation $46, X X, t(1 ; X)(p 34 ; \mathrm{q} 25)$ detected in 1 patient. The 
Karyotype results of all the patients showed in Table 2.

Table 2. The karyotype results of 79 patients with primary amenorrhea.

\begin{tabular}{lccc}
\hline \multirow{2}{*}{$\begin{array}{c}\text { Chromosomal } \\
\text { Categories }\end{array}$} & Karyotype & \multicolumn{2}{c}{$\begin{array}{c}\text { Number of } \\
\text { patients }\end{array}$} \\
\cline { 3 - 5 } & & n & \% \\
\hline Female Karyotype & $46, \mathrm{XX}$ & 55 & 69.6 \\
\hline Male karyotype & $46, \mathrm{XY}$ & 6 & 7.6 \\
\hline $\begin{array}{l}\text { Numerical } \\
\text { Abnormality }\end{array}$ & & & \\
\hline Monosomy & $\mathrm{X} 45, \mathrm{X}$ & 8 & 10.1 \\
\hline Turners Mosaic & $45, \mathrm{X} / 46, \mathrm{XX}$ & 3 & 3.8 \\
\hline $\begin{array}{l}\text { Presence of } \mathrm{XY} \\
\text { constitution }\end{array}$ & $45, \mathrm{X} / 46, \mathrm{XY}$ & 2 & 2.5 \\
\hline $\begin{array}{l}\text { Structural } \\
\text { Abnormality }\end{array}$ & & & \\
\hline $\begin{array}{l}\text { Marker } \\
\text { chromosome }\end{array}$ & $45, \mathrm{X} / 46, \mathrm{X}+\mathrm{mar} 2 \%$ & 1 & 1.3 \\
\hline $\begin{array}{l}\text { Isochromosome } \\
\text { Translocation } \mathrm{X} ; 1\end{array}$ & $46, \mathrm{XX}, \mathrm{t}(1 ; \mathrm{X})(\mathrm{p} 34 ; \mathrm{q} 25)$ & 1 & 1.3 \\
\hline
\end{tabular}

The distribution of diagnosis among 55 patients with female karyotype $46, \mathrm{XX}$ revealed 14 patients with MRKH, 2 patients with CAH and 1 patient with pure gonadal dysgenesis, while the remaining 38 patients still with unknown diagnosis. The diagnosis among 6 PA patients with male karyotype, 2 were CAIS, 1 was PAIS, and 3 patients with pure gondal dysgenesis (PGD) of undetermined cause.

According to the cytogenetic results of 18 patients with chromosomal abnormalities, the diagnosis were classical Turner Syndrome in 8 patients, mosaic Turner Syndrome in 9 patients and 1 patient with autosomal $\mathrm{X}$ translocation. The distribution of diagnosis among all patients showed in Figure 3.

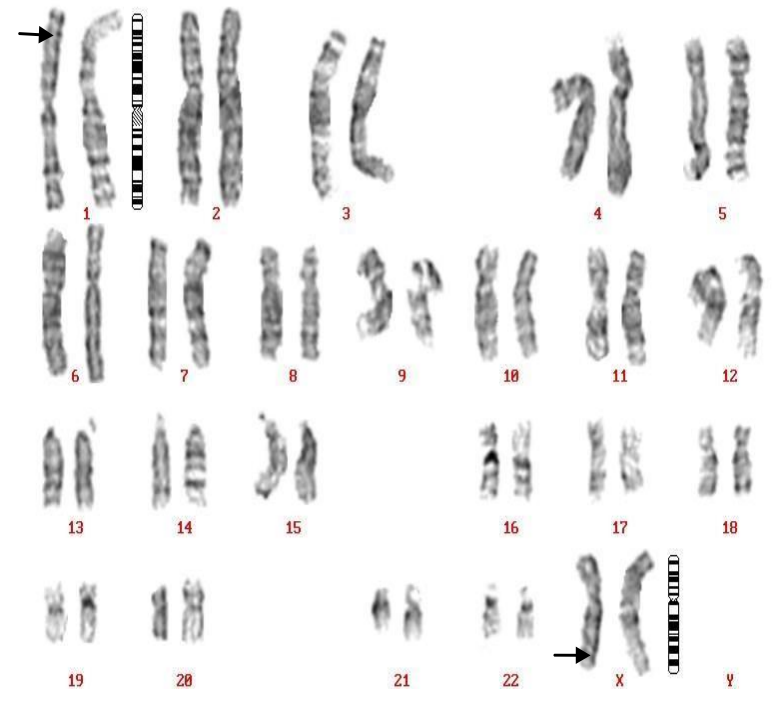

Figure 2. Karyotype result of patient with balanced translocation between $1 \mathrm{p}$ (arrow) and $\mathrm{Xq}$ (arrow)

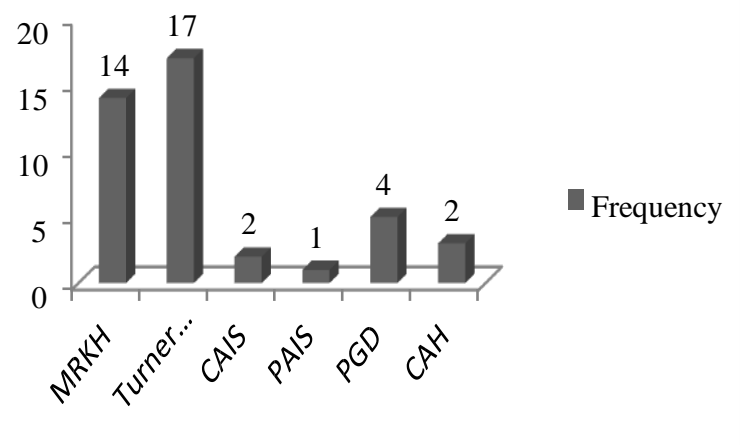

Figure 3. Frequency of diagnosis among 40 patients with primary amenorrhea

The result of scoring system and their karyotype revealed that scored 1 which was presented with primary amenorrhea only were 30 patients with female karyotype $(46, \mathrm{XX}) ; 1$ patient with male karyotype 46,XY; and 1 patient with mosaic Turner Syndrome 45,X(1\%)/46,XX(99\%). There were 25 patients with female karyotype $(46, X X)$ and 5 patients with male karyotype $(46, \mathrm{XY})$ matched with score 2 . Score 3 was demonstrated in 4 patients with classical Turner Syndrome $(45, \mathrm{X}) ; 4$ patients with mosaic Turner $(45 \mathrm{X}, 46, \mathrm{XX})$ and 1 patient with karyotype

46,XX,t $(1 ; \mathrm{X})(\mathrm{p} 34 ; \mathrm{q} 25)$. In This study 4 patients with classical Turner Syndrome $(45, X), 3$ patients with isochromosme $46, \mathrm{X}, \mathrm{i}(\mathrm{Xq}) / 45, \mathrm{X}$ and 1 patient with marker chromosome 45,X(98\%) /46,X,+mar (2\%) were matched with score 4 . (See Table 3)

Table 3. Scoring system and its related karyotype.

\begin{tabular}{ccc}
\hline Score & $\begin{array}{c}\text { Frequency of } \\
\text { Patients }\end{array}$ & Karyotype Results \\
\hline 1 & 30 & $46, \mathrm{XX}$ \\
& 1 & $45, \mathrm{X}(1 \%) / 46 . \mathrm{XX}(99 \%)$ \\
\hline 2 & 1 & $46, \mathrm{XY}$ \\
\hline 3 & 25 & $46, \mathrm{XX}$ \\
& 5 & $45, \mathrm{XY}$ \\
\hline & 4 & $45, \mathrm{X}(20 \%) / 46, \mathrm{XX}(80 \%)$ \\
& 1 & $45, \mathrm{X}(2 \%) / 46, \mathrm{XX}(98 \%)$ \\
& 1 & $45, \mathrm{X}(90 \%) / 46, \mathrm{XY}(10 \%)$ \\
& 1 & $46, \mathrm{X}(80 \%) / 46, \mathrm{XY}(20 \%)$ \\
& 1 & $45, \mathrm{X}$ \\
& 1 & $46, \mathrm{X}, \mathrm{i}(\mathrm{Xq})(10 \%) / 45 \mathrm{X}(90 \%)$ \\
& 4 & $46, \mathrm{X}, \mathrm{i}(\mathrm{Xq})(24 \%) / 45 \mathrm{X}(76 \%)$ \\
& 1 & $46, \mathrm{X}, \mathrm{i}(\mathrm{Xq})(20 \%) / 45 \mathrm{X}(80 \%)$ \\
& 1 & $45, \mathrm{X}(98 \%) / 46, \mathrm{X},+\operatorname{mar}(2 \%)$ \\
\hline
\end{tabular}

\section{DISCUSSION}

Attainment of menarche is important for female confidence and feminism. Primary amenorrhea can be a cause of psychological trauma in any female in reproductive age group. ${ }^{2}$ World Health Organization (WHO) ranked the primary amenorrhea as the sixth most common cause of infertility, hence the amenorrhea account $20 \%$ of all patients of infertility. ${ }^{6}$ The cause of primary amenorrhea are different and the role of genetic factors are significant. Several studies 
for cytogenetic analysis of primary amenorrhea patients have been done and aiming to understand the frequency and chromosomal constitution in those patients. ${ }^{10}$

In this study we demonstrated that $22.8 \%(18 / 79)$ PA patients with chromosomal abnormalities either numerical or structural. However, our study coordinate to the world wide estimated range for chromosomal abnormalities among primary amenorhea patients. In earlier studies the chromosomal abnormalities among primary amenorrhea patients reported to be counted in $20.63 \%$ in Egyptian patients, ${ }^{11} \quad 27.8 \%$ in Indian population, ${ }^{1,4,12} 20 \%$ in Iranian population ${ }^{13}$ and $41 \%$ in Mexican population. ${ }^{14}$ However, our study results was coordinated to the world wide estimated range for chromosomal abnormality among primary amenorrhea patients which was between $15.9 \%$ and $63.3 \%$. $^{5,7,15}$

All patients with sex chromosomal abnormalities in our study were Turner Syndrome either classical Turner Syndrome or Mosaic. This result was in line with previous studies which reported that Turner Syndrome is the most common observed chromosomal abnormality in primary amenorrhea and also strengthened the role of sex chromosome in the reproduction of female. , $^{4,16}$

The previous result revealed that classical Turner Syndrome detected in $30 \%(16 / 52)$ of primary amenorrhea patients in Turkish population, ${ }^{16}$ and $26.9 \%$ (7/ 26) of Indian patients. ${ }^{1,4,12,17}$ In current study Turner syndrome was detected in 17 out of 18. The high percentage of Turner Syndrome in our study could be due to patients selection and lack of genetic diagnostic in many referral hospitals in Java Island. So, most of patients referred to our center to do cytogenetic analysis.

The clinical profiles of Turner Syndrome patients showed that all patients with classical Turner Syndrome had short stature. Despite short stature, which seems to be the general clinical characteristic of Turner Syndrome, all other clinical stigmata were inconsistent, even in individuals with classical 45,X. The possible explanation for this issue that the physical manifestations of Turner Syndrome patients largely depends on the karyotype. ${ }^{16}$ The cause of short stature in Turner Syndrome suggested to be a homeobox gene, short stature homeobox (SHOX) gene in the pseudoautosomal region 1 (PAR1) is the major player and that haploinsuffiency of this gene leads to the growth failure. ${ }^{16,20}$ The other possible cause of short stature in Turner syndrome is inadequate production ofEstrogen,many of those with Turner Syndrome developosteoporosis.This can decrease height further, as well as exacerbate the curvature of the spine. ${ }^{14,20}$

Mosaic Turner Syndrome with XY constitution seen in $11.7 \%(2 / 17)$ of the patients, detection of $Y$ chromosome and its component is very important due to the risk of gonadoblastoma since the risk is quite high ranging from 10 to $20 \%$. While patients with mosaicism for 46,XY cell line or structural rearrangement of the $\mathrm{Y}$ chromosome mostly have masculinized external genitalia and are at increased risk for having gonadoblastoma and other gonadal tumor. $^{12,20,21}$ Thus, early intervention should be done for orchidectomy. ${ }^{22}$ In this study we observed 1 patient with marker chromosome 45,X(98\%)/46,X $\operatorname{mar}(2 \%)$ with clinical profile of this patient showed short stature and no other dysmorphic features, compared to the previous study which reported severe phenotype manifestations in those type of Turner variants, ${ }^{16}$ this could be due to the low percentage of marker X. Although, the conventional cytogenetic cannot detect the origin of marker chromosome, the molecular cytogenetic techniques, FISH, can accurately detect it. ${ }^{16,17}$ In this study we observed a patient with translocation between chromosome 1 and X. Besides primary amenorrhea, patient also had short stature. Translocation between $\mathrm{X}$ chromosome and autosome are known very often leads to fertility problems including PA and clinical features of Turner Syndrome and variable phenotype including developmental delay, thus, may due to nonrandom $\mathrm{X}$ inactivation. ${ }^{18}$ Especially when involving $\mathrm{q}$ arm of $\mathrm{X}$ chromosome, therefore, the finding may very well presented a balanced translocation resulting in the described phenotype (see figure 2 ). Some candidate genes located in the $\mathrm{q}$ arm of $\mathrm{X}$ chromosome may interrupted due to $\mathrm{X}$-autosome translocation such as DIAPH2, XPNEP2, DACH2, POF1B, CHM and NXF5. ${ }^{19}$ However, further cytogenetic/molecular analysis should be done to see the genotype and phenotype association in this patient

In our study the most common cause of primary amenorrhea in female karyotype patients was MRKH (14/55 ). The clinical profile of the patients showed normal Tanner stage in all patients, normal external genital and no dysmorphic features. With regards to the high number of MRKH patients, it needs molecular study to detect the associated gene mutations, ${ }^{23}$ although, the cause of mullerian gene is unknown, but it may be due to a mutation in the gene of the anti mullerian hormone or the Anti Mullerian Hormone (AMH) receptor. The underlying mechanism would be exposure to AMH acivity. No activating mutation is reported, in contrast with inactivating mutations which cause persistence of mullerian structures. $^{24}$

Male karyotype presented in a significant percentage $(7.6 \%)$ of patients with primary amenorrhoea although they appeared to be physically normal with some just appearing the height is taller for their age. In our study $\mathrm{Y}$ chromosome had been detected in $10 \%$ of PA patients, compared to previous study which demonstrated that $\mathrm{Y}$ chromosome was observed in $20 \%$ patients that referred as complain of primary amenorrhea. ${ }^{14}$ Although, this study demonstrated lower percentage, it could be due to selection of patients, preservation of some patients for karyotype analysis. Furthermore, conventional cytogenetic method can missed the $\mathrm{Y}$ component up to $9.3 \% .{ }^{21}$ Detection of Y chromosome complement and their composition is important in genetic counseling, because of the association with the risk of gonadoplastoma. ${ }^{9,12,20}$ 
In this study the most common cause of primary amenorrhea was gonadal dysgenesis Turner Syndrome followed by MRKH, pure gonadal dysgenesis, $\mathrm{CAH}$, CAIS and PAIS. The remaining 39 (49.3\%) patients still not diagnosed, it could be due to mutations and need molecular analysis for establishing the diagnosis. This study was agree with study in United States which demonstarated that gonadal dysgenesis as the commonest cause of primary amenorrhea and MRKH as the second most common cause. ${ }^{23}$ The same result had been reported from Korean study, which reported that the common causes of primary amenorrhea were gonadal dysgenesis $(28.0 \%, 37 / 132)$, followed by MRKH syndrome $(20.0 \%, 27 / 132) .{ }^{25}$ However, MRKH was the most prevalent cause of primary amenorrhea in Thailand, they reported that the 3 most common causes of primary amenorrhea were Müllerian agenesis/MRKH?

(39.7\%), gonadal dysgenesis $(35.3 \%)$, and hypogonadotropichypogonadism $\quad(9.2 \%) .{ }^{17,20,26}$ This verified that racial and environmental factors played an essential part in the causes of primary amenorrhea.

In the present study we made a scoring system from the clinical criteria and we matched the patients to appropriate scores. This scoring system can help to distinguish roughly possible karyotype results in situation of deficient genetic facilities before cytogenetic analysis hold out. Scoring system can be used to predict that PA patient with normal secondary sexual signs can be female or male karyotype results and cannot be a chromosomal abnormality based on clinical phenotypes. In contrast, PA with poor secondary sexual development with short stature and web neck can predict of chromosomal abnormalities. However, this scoring system needs further study with large sample population and measurement for validity and reliability.

A significant number of patients had sex chromosomal abnormalities, thus early cytogenetic investigation is prudent to guide further management. Patients with primary amenorrhea should be initially screened by primary physicians and gynecologists for presumptive diagnosis here in after, patients should receive prompt referral for genetic study. The reason for referral should be explained to the patient. If cytogenetic abnormalities are detected, a detail explanation should be given to the patient by a geneticist or gynecologist with experience in genetics. Counseling session should include the risk of premature ovarian failurefor patients withTurner's syndrome and the use of hormonal replacement therapy, the possibility of infertility in the future patients with mosaic Turner and the risk of gonadal malignancy for patients with XY gonadal dysgenesis. Counseling should be performed tactfully, bearing in mind that sensitive issues related to femininity are involved. An experienced counselor and clinical psychologist if needed would be helpful when patient facing with the gender identity.

\section{CONCLUSION}

Turner syndrome is the most common cause of primary amenorrhea in patients with chromosomal abnormalities. Cytogenetic analysis to distinguish the causes of primary amenorrhea is an important step especially in developing countries, although molecular analysis is now mandatory to detect the gene mutation. The new scoring system needs further study for measuring the reliability and validity.

\section{ACKNOWLEDGEMENT}

We would like to appreciate to the team work in Cytogenetic and Molecular unit Center for Biomedical Research (CEBIOR), we would also like to appreciate Disorders of Sex Development Team Faculty of Medicine Diponegoro University/Dr. Kariadi Hospital.

\section{REFERENCES}

1. Anagani M, Agrawal P, Radhika B, Sridevi D, Karee M (2017) Primary Amenorrhea - A One Year Review. ObstetGynecolInt J 2017:6(1):2-5.

2. Merin T, Rema D, Preetha T, Amudha S, Jayalakshamma J, Mary M. Amenorrhea : Cytogenetic Studies and Beyond.American Journal of Molecular and Cellular Biology2012; 1: 25-37.

3. TahirM.Malla, FayazA.Dar, Arshad A. Frequency and pattern of cytogenetic alterations in primary amenorrhea patients of Kashmir , North India. Egypt $J$ Med Hum Genet. 2016;17(1):25-31.

4. Butnariu L, Covic M, Ivanov I, Bujoran C, Gramescu M, Gorduza EV. Clinical and cytogenetic correlation in primary and secondary amenorrhea: retrospective study on 531 patients.Journal of medicine, 2011;19(2):51-60.

5. Practice T, Medicine R. Current evaluation of amenorrhea. Journal of sterility and fertility;2008;90(5):21-5.

6. Vijayalakshmi J, Koshy T, Kaur H, Mary FA, Selvi R, Parvathi VD, et al. Cytogenetic Analysis of Patients with Primary Amenorrhea.Int J Hum Genet 2010;10(3):71-6

7. Jahan S, Shermin S, Habib SH, Nayer R. Gynecology \& Obstetrics Kallmann , s Syndrome: A Rare Cause of Primary Amenorrhoea.JournalGynecol Obstet;2014;4(9).

8. Klein D, Poth M. Amenorrhea: An Approach to Diagnosis and Management.AmFam Physician. 2013;87(11):781-8.

9. LeelavathyNanjappa, SayeeRajangam et al. Genotype - Phenotype Correlation in 46 , XY Females.KuwaitMedical Journal; 2008;40 (3): 225-9.

10. Hasan A, Hakan T, M. Hamza M.A New Female Patient with 47 , XXY Karyotype and SRY. Andrology-Open Access; 2016;5(1):10-13.

11. Chandrayan P, Parekh U, Jain N, Chandrayan P. Mullerian duct anomalies presenting with primary amenorrhoea.Journal of Reproduction, Contraception, obstetrics and gynecology; 2016;5(2):300-50

12. Pokale Y, Jadhav A, Kalthe B, Kate U. A patient of primary amenorrhea with 46, XY Karyotype : 
Androgen insensitivity syndrome (AIS).international journal of pharmacy and Biological Sciences.2013;5(5):2278-3008

13. Okafor et al. Imperforate Hymen Presenting with Massive Hematometra and Hematocolpos: A case Report., GynecolObstet; 2015;5(10):328.

14. Allahbadia G, Human F. An Update on the Causes of Primary and Secondary Amenorrhea along with Aetiopathogenesis and Therapeutic Management Monograph Series. avid SciMonogr Ser. 2016;9(6)

15. Master-hunter $\mathrm{T}$, Medical $\mathrm{M}$, Arbor $\mathrm{A}$. Amenorrhea: Evaluation and Treatment Am Fam Physician;2006; 4 (8): 25-30.

16. Gürsoy S, Kılıçarslan ÖA, Bozkaya ÖG, Bora E, Ünal N, Erçal D. Clinical and Cytogenetic Evaluations of Patients with Turner Syndrome: Are We Aware Enough ?Erciyes Med journal ; 2017;39(1):12-5.

17. Kim KS, Kim J. Disorders of Sex Development. Korean Journal of Urology. 2012;53(1):1-8.

18. Leppig KA, Disteche CM. Ring $X$ and other structural $\mathrm{X}$ chromosome abnormalities: X inactivation and phenotype. SeminReprod Med. 2001;19:147-57)

19. Vitek WS, Pagidas K, Gu G, Pepperell JR, Simpson JL, Tantravahi U, et al. Xq;autosome translocation in POF: Xq27.2 deletion resulting in haploinsufficiency for SPANX. J Assist Reprod Genet. 2012; 29 ( 1): 63-6)
20. Utiïrrezetal.prevalence of chromosomal abrration in Mexican women with primary amenorrhea.Reprod Biomed online; 2007.

21. Marzuki NS, Anggaratri HW, Suciati LP, Ambarwati DD, Paramayuda C, Kartapradja H, et al. Diversity of sex chromosome abnormalities in a cohort of 95 Indonesian patients with monosomy X. MolCytogenet; 2011;4(1):23.

22. Motos M, Mendoza N. Androgen insensitivity syndrome Androgen insensitivity syndrome.JournalsEndocrinolgy; 2014; 1(2), 20-5.

23. Cox L, Liu JH. Primary ovarian insufficiency: an update.internationalJournal of Women Health; 2014;235-43.

24. Parikh RM, Nakum K, Kadikar GK, Gokhle A V. Mullerian anomalies: a cause of primary amenorrhea.Int $J$ ReprodContraceptObstet Gynecol. 2013;2(3):3-7.

25. Mamoojee Y, Jones P, Stewart J, Choudhary M, Quinton R. Spontaneous resolution of secondary amenorrhoea in a patient with mosaic Turner' $\mathrm{s}$ Syndrome. Journal Endocrine Abstracts; 2016;3(2);52-9.

26. Kwon S, Chae H, Lee K, Kim S, Kim C, Kang B. Causes of amenorrhea in Korea : Experience of a single large center.clinical and experimental medicine journal; 2014;41(1):29-32. 